SILVA, M.C., MOURA, M.S. e REIS, D.O. A importância da histopatologia para a inspeção federal na confirmação de lesões pulmonares suspeitas de tuberculose em bovinos abatidos.

PUBVET, Londrina, V. 5, N. 8, Ed. 155, Art. 1047, 2011.

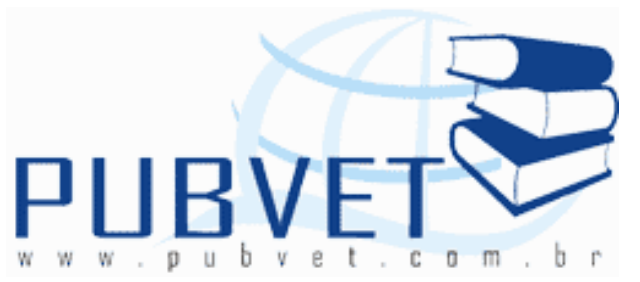

PUBVET, Publicações em Medicina Veterinária e Zootecnia.

\title{
A importância da histopatologia para a inspeção federal na confirmação de lesões pulmonares suspeitas de tuberculose em bovinos abatidos
}

Mariana Camilo da Silva ${ }^{1 *}$, Mariela Silva Moura ${ }^{1}$, Denio Oliveira Reis ${ }^{2}$

${ }^{1}$ Graduanda em Medicina Veterinária, Universidade Federal de Uberlândia. Uberlândia, MG.

${ }^{2}$ Docente da Faculdade de Medicina Veterinária, Universidade Federal de Uberlândia. Uberlândia, MG.

*Autor para correspondência: Rua Ceará, s/n, Bloco 2D, CEP 38400-902, Uberlândia, MG, Brasil. E-mail: mari_vet20@hotmail.com

\section{Resumo}

A tuberculose bovina é uma doença que apresenta significativos reflexos econômicos, bem como aqueles que afetam diretamente ou indiretamente a saúde pública. Muitos animais infectados pelo agente causador da referida doença são abatidos diariamente, causando uma situação preocupante, pois como é sabido, o diagnóstico da doença no âmbito de matadouro frigorífico, se restringe prioritariamente ao diagnóstico macroscópico das lesões suspeitas, o que eventualmente pode levar a um diagnóstico equivocado. Assim, o veterinário, não raro se vê em uma situação difícil, quando na identificação da lesão na sala de abate. A partir disso, coletaram-se em um frigorífico da região de Uberlândia, 42 amostras de carcaças desviadas ao DIF (Departamento de 
SILVA, M.C., MOURA, M.S. e REIS, D.O. A importância da histopatologia para a inspeção federal na confirmação de lesões pulmonares suspeitas de tuberculose em bovinos abatidos. PUBVET, Londrina, V. 5, N. 8, Ed. 155, Art. 1047, 2011.

Inspeção Final), como suspeitas de tuberculose, para serem diagnosticadas através da histopatologia para a confirmação da doença. As amostras foram fixadas em formol a $10 \%$ e conduzidas para o Departamento de Histopatologia da UFU para os procedimentos técnicos na preparação das lâminas. Os resultados mostraram que $69,04 \%$ eram positivas para tuberculose e $30,95 \%$ foram classificadas como linfadenites inespecíficas. Avaliaram-se estatisticamente as variáveis idade, raça e sexo, apresentando dependência estatística significativa a variável sexo, e independência entre as variáveis idade e raça, todas analisadas em relação à classificação da tuberculose como típica ou não típica. Todas as amostras eram de animais fêmeas, provenientes do Triângulo Mineiro e Alto Paranaíba.

Palavras-chave: Mycobacterium bovis, folículo tuberculoso, nódulo tuberculoso, linfadenite granulomatosa, histopatologia.

\section{The importance of histopathology for the federal inspection in the confirmation of lung lesions suspicious of tuberculosis in cattle slaughtered}

\section{Abstract}

Bovine tuberculosis is an illness which has indirect influence on economy, as well as public health. Many animals infected by the agent that causes the sickness are slaughtered very often, and it becomes a worrying situation, once the diagnostic of tuberculosis at slaughter- house is primary restricted to macroscopic diagnostic of the suspected lesions, which can lead to a wrong diagnostic. So, the veterinary is put in a difficult situation in the identification of lesions in the slaughter- room. Forty two samples of carcasses that were removed for DIF (Department of Finally Inspection) were collected in a slaughter- house of Uberlândia due to suspicion of tuberculosis. They were analyses and diagnosticated by the histopathology so that the sickness could be confirmed. The samples were put in formaldehyde $10 \%$ and led to Department de Histopathology UFU for technical procedus in the preparation of 
SILVA, M.C., MOURA, M.S. e REIS, D.O. A importância da histopatologia para a inspeção federal na confirmação de lesões pulmonares suspeitas de tuberculose em bovinos abatidos.

PUBVET, Londrina, V. 5, N. 8, Ed. 155, Art. 1047, 2011.

slides. The results showed that $69,04 \%$ of the samples really confirmed tuberculosis and 30, 95\% were classified as inespecific linfadenites. The characteristics age, race and sex were evaluated statically significative dependence the characteristic sex, and independence between the characteristics age and sex, all of them analyses in relation to the classification of tuberculosis in typical or atypical. All the samples belonged to female animals which come from Triângulo Mineiro e Alto Paranaiba.

Keywords: Mycobacterium bovis, follicle tuberculosis, tuberculosis nodules, granulomatous lymphadenitis, histopathology.

\section{Introdução}

A tuberculose é uma zoonose de evolução crônica causada pelo Mycobacterium bovis e caracteriza-se pelo desenvolvimento de lesões nodulares denominadas tubérculos. Essas lesões podem ser localizadas em qualquer órgão do animal, sendo que as lesões iniciais geralmente se restringem ao parênquima pulmonar que poderão se espalhar e se desenvolverem nos linfonodos do mediastino, podendo ficar ali retidas e na forma inativa, e posteriormente reiniciar sua multiplicação e causar uma reação inflamatória expansiva que posteriormente levará a uma necrose. Com o passar do tempo poderá fibrosar e logo depois se calcificar. É possível também ocorrer liquenificação do material caseoso que poderá se depositar em qualquer outro local, espalhando o bacilo.

O gênero Mycobacterium sp. causador da tuberculose no homem e nos animais domésticos, inclui espécies patogênicas, sendo as mais comuns e importantes o Mycobacterium tuberculosis que infecta exclusivamente o homem, podendo acidentalmente acometer o bovino, não provocando grandes alterações nesse último hospedeiro, e o Mycobacterium bovis que infecta os bovinos, podendo também ocasionalmente contaminar o homem por meio de leite e carne 'in natura' infectados com o bacilo. 
SILVA, M.C., MOURA, M.S. e REIS, D.O. A importância da histopatologia para a inspeção federal na confirmação de lesões pulmonares suspeitas de tuberculose em bovinos abatidos.

PUBVET, Londrina, V. 5, N. 8, Ed. 155, Art. 1047, 2011.

A via de transmissão mais comum é a via aerógena, através da inalação de partículas/aerossóis em suspensão no ar, sendo possível também por meio da via oral. Outras vias como a transplacentária, lactogênica, ou o contato com secreções e excreções do portador também são fontes de transmissão da doença. É fato que a contaminação do leite cru é uma das principais fontes de infecção humana pelo bacilo bovino e que o risco de contrair o bacilo através da ingestão de produtos cárneos é menor devido a pouca incidência do Mycobacterium sp. no tecido muscular no entanto não se deve ignorar esse fato.

Zelar pela saúde pública é uma das funções mais importante do veterinário, que rotineiramente decide sobre a destinação de uma carcaça assim como seus subprodutos, sempre visando á segurança e sanidade para a saúde pública. A partir disso, entende-se o papel fundamental do médico veterinário no serviço de inspeção, que frente a seus conhecimentos específicos em patologia, epidemiologia, controle de doenças zoonóticas, está apto a garantir a qualidade para a população humana e animal.

O presente estudo será conduzido de forma a permitir, que haja a destinação adequada e devida das carcaças e vísceras portadoras de lesões suspeitas ou não de tuberculose considerando que o trabalho da inspeção sanitária em matadouros frigoríficos se fundamenta no diagnostico macroscópico, em que a tuberculose bovina não foge a regra.

Portanto, o objetivo específico dessa pesquisa realizada é incorporar á rotina de inspeção post-mortem o diagnóstico histopatológico, nos casos que gerem suspeitas de tuberculose, pois com essa prática, a inspeção sanitária post-mortem irá estar respaldada tanto para a identificação da doença, quanto a destinação correta das carcaças e respectivas vísceras, proporcionando uma maior segurança e sanidade a saúde publica, além de colaborar na minimização dos impactos na economia da produção bovina causados pela tuberculose. 
SILVA, M.C., MOURA, M.S. e REIS, D.O. A importância da histopatologia para a inspeção federal na confirmação de lesões pulmonares suspeitas de tuberculose em bovinos abatidos.

PUBVET, Londrina, V. 5, N. 8, Ed. 155, Art. 1047, 2011.

\section{Material e métodos}

Para a realização da pesquisa feita, foram coletadas amostras de lesões de tuberculose, de um matadouro frigorífico próximo à região de Uberlândia, que posteriormente foram encaminhadas ao Laboratório de Histopatologia da UFU. Essas amostras foram coletadas do período de Janeiro de 2008 a Agosto de 2008.

Nesse período foram abatidos 2699 animais, dos quais 2652 eram fêmeas e 47 machos, provenientes da região do Triângulo Mineiro. As amostras que foram colhidas eram de carcaças e vísceras oriundas de fêmeas que foram desviados ao Departamento de Inspeção Final (DIF), que ao passarem pela linha de Inspeção Federal apresentaram lesões de constatações duvidosas. De todas essas carcaças desviadas, as amostras que foram coletadas se restringiam ao linfonodos que envolvia toda a região pulmonar e eram descritas em uma ficha criada para a pesquisa que constava da data de abate, data da coleta, sexo, idade, raça e procedência.

Dessa forma, o médico veterinário avaliava e julgava o destino correto da carcaça e de suas respectivas vísceras, encaminhando aquelas caracterizadas por lesões típicas de tuberculose para o aproveitamento parcial ou condenação total, e seqüestrava aquelas de lesões duvidosas obedecendo o que é preconizado no Art. 196 descrito RIISPOA (1952) (Regulamento de Inspeção Industrial e Sanitária de Produtos de Origem Animal), do Ministério da Agricultura.

Para a análise microscópica foi feito o seguinte processo: (JUNQUEIRA e CARNEIRO, 1995) Inicialmente na coleta das amostras os fragmentos retirados mediram aproximadamente um a dois centímetros de diâmetro e com espessura média de cinco milímetros. Os fragmentos ao serem retirados envolviam a parte de lesão e a parte de tecido sadio. A partir disso, foram imersos nos frascos de coletor universal contendo formol a $10 \%$ e ali permaneceram por no mínimo 24 horas para fixação. 
SILVA, M.C., MOURA, M.S. e REIS, D.O. A importância da histopatologia para a inspeção federal na confirmação de lesões pulmonares suspeitas de tuberculose em bovinos abatidos.

PUBVET, Londrina, V. 5, N. 8, Ed. 155, Art. 1047, 2011.

As amostras então foram encaminhadas para o Laboratório de Histopatologia da UFU, de onde se iniciou a preparação das amostras. O primeiro procedimento feito foi o processo de desidratação onde os fragmentos formam suspensos em solução desidratante que envolveu:

- - Uma hora em álcool 85\%

- -Uma hora em álcool 95\%

- -Uma hora em álcool absoluto (1)

- -Uma hora em álcool absoluto (2)

- -Uma hora em álcool absoluto (3)

Seguindo o processo, ocorreu a etapa da diafanização com o uso do xilol, passando por um tempo total de 45 minutos divididos em 3 etapas de 15 minutos cada.A impregnação pela parafina foi à próxima etapa que ocorreu também em um tempo de 45 minutos divididos em 3 etapas de 15 minutos cada.Os fragmentos ficaram impregnados no material parafinado e foram colocados em uma estufa a $56^{\circ} \mathrm{C}$ onde permaneceram por mais 45 minutos em outras três etapas de 15 minutos cada.A partir disso, foi possível fazer 'bloquinhos' que posteriormente foram cortados pelo micrótomo em faixas finíssimas com 6 micras de espessura.

Dessa maneira, chegou-se a parte preliminar que é a junção da lâmina com a lamínula mais o fragmento com o bálsamo do Canadá que funciona como um aderente entre a lâmina e a lamínula. Por fim a lâmina já pronta pode ser mergulhada na solução corante de hematoxilina de Harris e logo depois na de eosina. Após o processamento, cada lâmina foi levada a uma estufa a $37^{\circ} \mathrm{C}$ por uma hora para secá-la e assim finalmente pode ser lida ao microscópio óptico em objetivas de 10x e 40x, verificando em algumas laminas as alterações celulares característicos de lesões de tuberculose.

Na metodologia para verificar a ocorrência de diferenças significativas entre os grupos e em cada tempo, utilizou-se a analise de variância inteiramente casualizada (BANZANTO e KRONKA, 1989). Em principio, verificaram-se as pressuposições do modelo (homogeneidade da variância dos 
SILVA, M.C., MOURA, M.S. e REIS, D.O. A importância da histopatologia para a inspeção federal na confirmação de lesões pulmonares suspeitas de tuberculose em bovinos abatidos.

PUBVET, Londrina, V. 5, N. 8, Ed. 155, Art. 1047, 2011.

erros estimados e normalidade da distribuição dos erros estimados). Quando da aplicação da analise de variância, ocorreu a rejeição das hipóteses da igualdade das medias, utilizou-se para a comparação das mesmas, o teste de Scott-Knott (SCOTT e KNOTT, 1974).

Quando se trabalhou com variáveis qualitativas utilizou-se o teste de qui-quadrado via simulação de Monte Carlo. Valores de $p<0,05$ indicaram significância estatística. Desta forma compararam-se as freqüências de ocorrência e não ocorrência das variáveis estudadas.

\section{Resultados e Discussão}

Dos 2699 animais abatidos e inspecionados pelo SIF (Serviço de Inspeção Federal), num matadouro frigorífico na região de Uberlândia, durante os meses de Janeiro a Agosto de 2008, 42 carcaças suspeitas de lesões de tuberculose foram desviadas para o DIF (Departamento de Inspeção Final) pelos agentes de inspeção para serem criteriosamente inspecionadas pelo médico veterinário responsável. A percentagem de animais que foram desviadas para o DIF não ultrapassou de 1,58\%.

Do total de animais abatidos nesse período, 2652 (98,25\%) eram fêmeas e $47(1,74 \%)$ eram machos. Todas as 42 carcaças desviadas eram de fêmeas, com idade entre 2 a 5 anos, das raças nelore,cruzado e holandês e todas procedentes da região do Triângulo Mineiro a Alto Paranaíba. Pinto (2003) ressalta que há importância também em avaliar a prevalência da tuberculose fazendo uma investigação baseada em uma inquisição epidemiológica em matadouros, frigoríficos buscando a partir de carcaças e vísceras destinadas ao DIF (Departamento de Inspeção Final) ,identificar alterações anatomopatológicas típicas de um folículo tuberculoso, que dessa maneira permitirá, assim o conhecimento prévio das características epidemiológicas,mostrar a importância da inspeção que deve ser respaldada pela técnica histopatológica principalmente naqueles estabelecimentos em que há o abate de vacas leiteiras de descarte. 
SILVA, M.C., MOURA, M.S. e REIS, D.O. A importância da histopatologia para a inspeção federal na confirmação de lesões pulmonares suspeitas de tuberculose em bovinos abatidos.

PUBVET, Londrina, V. 5, N. 8, Ed. 155, Art. 1047, 2011.

$\mathrm{Na}$ confirmação do diagnóstico histopatológico das 42 lâminas, para serem classificadas como um folículo tuberculoso típico foi considerado que deveriam ser visto no campo microscópico, áreas com necrose caseosa, presença de células de Langhans ou células gigantes e áreas de mineralização. Caso essas características não estivessem presentes no campo visual, eram então julgadas como uma linfadenite inespecífica. Reis et al. (1995) afirma que muitas vezes as lesões achadas em frigoríficos, não seguem especificamente os padrões anatomopatológicas que ocorrem com freqüência, gerando dúvidas para o médico veterinário, que pode fazer com que o profissional confunda a tuberculose com lesões de linfossarcoma ou linfadenites inespecíficas.

Os resultados das 42 lâminas mostraram que 29 amostras (69,04\%) eram típicas de tuberculose, e 13 amostras (30,95\%) não típicas da doença, enquadrando-se em linfadenites inespecíficas. Em países que tem rígido programa de controle para a tuberculose, os autores Claxton (1979) e Errico et al. (1980) pesquisaram e encontraram com a aplicação da técnica histopatológica, que $40,8 \%$ e até $74 \%$ das lesões semelhantes a tuberculose eram causadas por outros agentes.

Ao fim das análises estatísticas entre as variáveis e a classificação da tuberculose como típica ou não típica, foi confirmada a independência significativa entre as variáveis idade ( $p$-valor $=0,831)$ e raça ( $p$-valor $=0,827$ ), pois o resultado da significância $>0,05$ mostra que não há dependência entre essas, conforme Scott-Knott, 1974 (Tabela 1 e 2).

Para a variável sexo $(p$-valor $=0,000)$ houve dependência estatisticamente significativa, no qual o valor de significância $<0,05$ é julgado como dependente entre as variáveis, afirma (SCOTT e KNOTT,1974). No entanto, o resultado da variável sexo, pode ser justificado pela percentagem de $100 \%$ das carcaças seqüestradas, serem todas oriundas de animais fêmeas (Tabela 3). 
SILVA, M.C., MOURA, M.S. e REIS, D.O. A importância da histopatologia para a inspeção federal na confirmação de lesões pulmonares suspeitas de tuberculose em bovinos abatidos. PUBVET, Londrina, V. 5, N. 8, Ed. 155, Art. 1047, 2011.

Tabela 1. Tabela de continência da variável A nas classes 1 (classificação da tuberculose) e da variável B nas classes 1 (idade) com p-valor do teste de qui-quadrado de independência via simulação de Monte Carlo*.

\begin{tabular}{|l|c|c|c|c|}
\hline & & Classificação da tuberculose & & \\
\hline & & Não típica & Típica & Total \\
\hline Idade & $\mathbf{2}$ & $2,4 \%$ & $14,3 \%$ & $16,7 \%$ \\
\hline & $\mathbf{3}$ & $11,9 \%$ & $21,4 \%$ & $33,3 \%$ \\
\hline & $\mathbf{4}$ & $7,1 \%$ & $16,7 \%$ & $23,8 \%$ \\
\hline & $\mathbf{5}$ & $9,5 \%$ & $16,7 \%$ & $26,2 \%$ \\
\hline & Total & $31,0 \%$ & $69,0 \%$ & $100 \%$ \\
\hline
\end{tabular}

${ }^{*} \mathrm{p}$-valor $=0,831$

Tabela 2. Tabela de continência da variável A nas classes 1 (classificação da tuberculose) e da variável B nas classes 1 (raça) com p-valor do teste de qui-quadrado de independência via simulação de Monte Carlo*.

\begin{tabular}{|l|c|c|c|c|}
\hline & & Classificação da tuberculose & & \\
\hline & & Não típica & Típica & Total \\
\hline Raça & Cruzado & $7,1 \%$ & $23,8 \%$ & $31,0 \%$ \\
\hline & Holandês & $16,7 \%$ & $31,0 \%$ & $47,6 \%$ \\
\hline & Nelore & $7,1 \%$ & $14,3 \%$ & $21,4 \%$ \\
\hline & Total & $31,0 \%$ & $69,0 \%$ & $100 \%$ \\
\hline
\end{tabular}

*p-valor $=0,827$ 
SILVA, M.C., MOURA, M.S. e REIS, D.O. A importância da histopatologia para a inspeção federal na confirmação de lesões pulmonares suspeitas de tuberculose em bovinos abatidos. PUBVET, Londrina, V. 5, N. 8, Ed. 155, Art. 1047, 2011.

Tabela 3: Tabela de continência da variável A nas classes 1(classificação da tuberculose) e da variável B nas classes 1 (sexo) com p-valor do teste de qui-quadrado de independência via simulação de Monte Carlo*.

\begin{tabular}{|c|c|c|c|c|}
\hline & & \multicolumn{2}{|c|}{ Classificação da tuberculose } & \multirow[b]{2}{*}{ Total } \\
\hline & & Não típica & Típica & \\
\hline \multirow[t]{2}{*}{ Sexo } & Fêmea & $31,0 \%$ & $69,0 \%$ & $100 \%$ \\
\hline & Total & $31,0 \%$ & $69,0 \%$ & $100 \%$ \\
\hline
\end{tabular}

$* \mathrm{p}$-valor $=0,000$

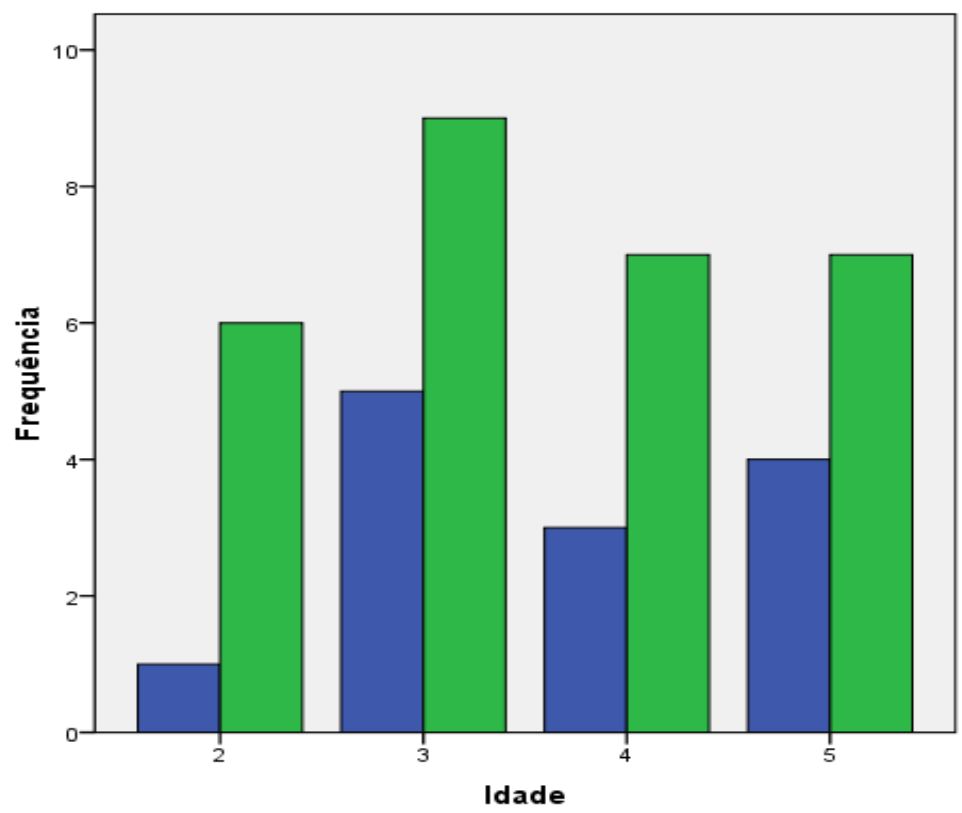

Gráfico 1-Representa as freqüências entre a variável idade e a classificação da tuberculose. Freqüência maior entre animais de três anos ou 36 meses de idade. 
SILVA, M.C., MOURA, M.S. e REIS, D.O. A importância da histopatologia para a inspeção federal na confirmação de lesões pulmonares suspeitas de tuberculose em bovinos abatidos. PUBVET, Londrina, V. 5, N. 8, Ed. 155, Art. 1047, 2011.

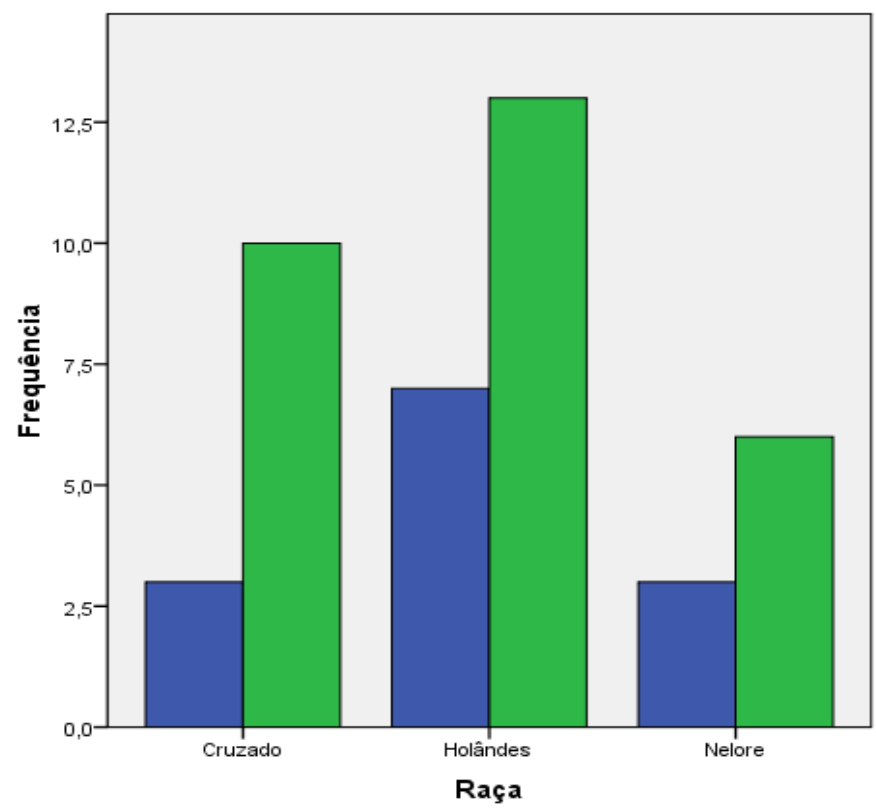

Gráfico 2 - Representa as freqüências entre a variável raça e a classificação da TB. Freqüência maior nos animais da raça holandês.

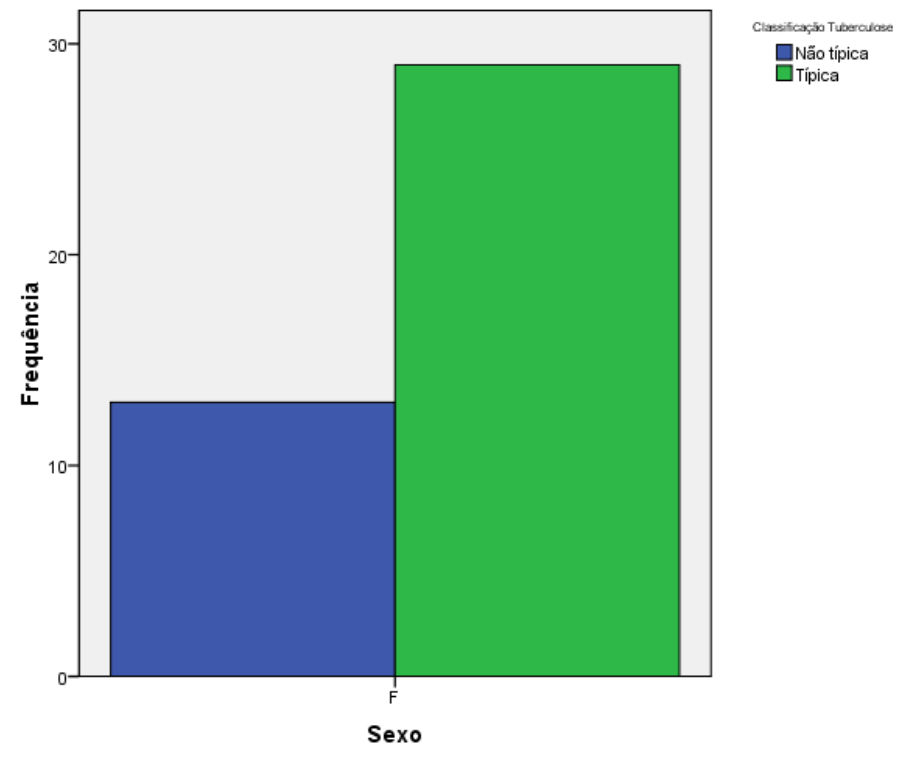

Gráfico 3- Representa as freqüências entre a variável sexo e a classificação da TB. Freqüência maior nos animais do sexo feminino. 
SILVA, M.C., MOURA, M.S. e REIS, D.O. A importância da histopatologia para a inspeção federal na confirmação de lesões pulmonares suspeitas de tuberculose em bovinos abatidos. PUBVET, Londrina, V. 5, N. 8, Ed. 155, Art. 1047, 2011.

\section{Conclusão}

Com base nos resultados encontrados no presente trabalho, concluímos ser de fundamental importância o uso da técnica histopatológica caracterizada por ser um método rápido e seguro para o diagnóstico final de tuberculose e outras patologias em matadouros frigoríficos, que servirá como um recurso que respaldará o serviço de inspeção sanitária, assegurando ao médico veterinário maior precisão na destinação de carcaças e vísceras de bovinos.

\section{Referências}

BANZATO, D. A. KRONKA, S. N. Experimentação Agrícola. Jaboticabal, FUNEP, p 247, 1989.

BRASIL. Ministério da Agricultura e Pecuária. Serviço de Inspeção Federal. Decreto n.30.691 de 29 de Março de 1952, Art.196. Disponível em:<htpp://www.agricultura.gov/sda/dipoa>. Acesso em 14 de outubro de 2008.

CLAXTON, P. D.; EAMENS, G. J.; MYLREA, P. J. Laboraty diagnosis of bovine tuberculosis. Australian Veterinary Journal. Queensland, v.55, p.514-519, nov., 1979.

ERRICO, F.; PERDOMO, E.; BERMUDEZ, J. Estudios de lesions similares a tuberculosis en bovines del Uruguay. Veterinaria, Montevideo, v.2, p.21-24, 1980.

JUNQUEIRA. L. C.; CARNEIRO, J. Histologia Básica, 8a ed. Rio de Janeiro: Editora Guanabara Koogan, 1995.

PINTO, P. S. A. Atualização em Controle da Tuberculose no Contexto de Inspeção de Carnes. Bioscience Journal, Uberlândia, v.19, n.1, p.115-121, 2003.

REIS, D. O.; ALMEIDA, L. P.; FARIA, A. R. Estudo comparativo entre linfossarcoma,tuberculose e linfadenite inespecífica ocorridas em bovinos abatidos e a confirmação histopatológica.Revista Higiene Alimentar.São Paulo,v.9,n.35,1995

SCOTT, A. J.; KNOTT, M. A. A Cluster analysis method for grouping means in the analysis of variance. Biometrics, Raleigh, v.30, n.3, p.507-512.1974. 